\title{
Deslizamentos funcionais do verbo achar. gramaticalização em evidência
}

\author{
Functional changes of the verb achar: grammaticalization in evidence
}

\author{
Iolanda Ferreira dos Santos * \\ Universidade Estadual de Santa Crur. \\ Ilhéus, BA, Brasil \\ Gessilene Silveira Kanthack ${ }^{* *}$ \\ Universidade Estadual de Santa Cruz. \\ Ilhéus, BA, Brasil
}

\begin{abstract}
Resumo: Objetivamos, neste trabalho, apresentar os resultados de uma pesquisa que investigou os usos do verbo achar, a partir de uma amostra constituída de fanfiction, narrativa ficcional escrita e divulgada por fãs que se apropriam de enredos e personagens de produtos midiáticos para criarem histórias paralelas ao original. Tendo como base pressupostos sobre gramaticalização (HOPPER; TRAUGOTT, 1993; GONÇALVES et al., 2007), verificamos se os usos evidenciam ou não um caso de mudança linguística. Os resultados apontam que o verbo achar desempenha, além de sua função lexical [valor + concreto; - gramatical], a função de modalização [valor +abstrato; + gramatical], estratégia linguística que possibilita o falante veicular seu ponto de vista sobre o que diz. Esta última função evidencia uma abstratização do significado, propriedade característica da mudança por gramaticalização.
\end{abstract}

Palavras-chave: Verbo achar. Usos. Fanfiction. Gramaticalização.

\begin{abstract}
This work aims at presenting the results of a research on the uses of the verb achar in a sample of Fanfiction, a fictional text written and published by fans using characters and plots from mediatic products to create stories parallel to the original ones. Based on grammaticalization studies (HOPPER; TRAUGGOT, 1993 and GONÇALVES et al., 2007), we verified whether the uses showed a case of linguistic change. The results demonstrate that the verb achar, besides its lexical function [value +concrete; -grammatical], performs the function of modalization [value +abstract; +grammatical], a linguistic strategy which allows the speaker to express his attitude towards what he says. This function evidenciates that the meaning becomes abstract, one of the features of the change by grammaticalization.
\end{abstract}

Keywords: Verb achar. Uses. Fanfiction. Grammaticalization.

\footnotetext{
* Mestranda do Programa de Pós-Graduação em Letras: Linguagens e Representações, Universidade Estadual de Santa Cruz (UESC), Ilhéus-BA, Brasil. E-mail: iolandaferreiradossantos@gmail.com.

** Doutora em Linguística pela Universidade Federal de Santa Catarina-UFSC/Florianópolis-SC, Brasil, Professora da Universidade Estadual de Santa Cruz-UESC/Ilhéus-BA. Pós-doutoranda no Programa de Pós-Graduação em Linguística/PPGLin da Universidade Estadual do Sudoeste da Bahia, Vitória da Conquista-BA, Brasil, Brasil. E-mail: gskanthack@yahoo.com.br).
} 


\section{INTRODUÇÃO}

$\mathrm{Na}$ perspectiva do Funcionalismo Linguístico, conforme Neves (2018), três pressupostos são de extrema importância: (i) a língua deve ser entendida como um sistema funcional que serve como instrumento de interação verbal; (ii) a gramática não deve ser entendida como um produto acabado, mas, sim, susceptível às pressões do uso; (iii) a análise dos fatos linguísticos deve partir dos usos efetivos, uma vez que compreender a língua como um sistema funcional e adaptativo, que permite ao falante fazer escolhas apropriadas a seus interesses comunicativos, implica recorrer a usos reais de língua.

Assumindo pressupostos como esses, realizamos uma pesquisa ${ }^{1}$ tendo como objeto o verbo achar, com o intuito de verificar as funções que ele desempenha em situações concretas de língua. Partindo do pressuposto de que as estruturas são modeladas conforme o uso que os falantes fazem da língua, o esperado é encontrar esse verbo sendo usado com funções que ultrapassem seu sentido básico, funções que revelem mudança por gramaticalização.

A propósito, gramaticalização, termo introduzido pelo francês Antoine Meillet, em 1912, foi usado, inicialmente, para explicar a passagem de uma palavra autônoma à função de elemento gramatical, uma trajetória de mudança firmada pela regularização do uso da língua (cf. GONÇALVES et al., 2007). Com o passar do tempo, esse conceito foi sendo aperfeiçoado, e, atualmente, um dos que se destacam nos estudos sobre gramaticalização é o de Hopper e Traugott (1993): processo através do qual, itens lexicais, em determinados contextos linguísticos, assumem funções gramaticais, e, uma vez gramaticalizados, continuam a desenvolver novas funções gramaticais.

Considerada como um dos casos de mudança mais comuns nas línguas em geral, a gramaticalização está associada à necessidade constante de o falante ajustar as formas e as funções dos itens linguísticos para atender às necessidades comunicativas. Nesse processo, falante e ouvinte "têm de se esforçar para se fazer entender e para tentar entender, negociando e adaptando funções e formas para levar sua interação linguística adiante, o que instiga a mudança" (TAVARES, 2012, p. 35).

E é justamente nessa dinâmica que podemos perceber os deslizamentos funcionais empreendidos pelo verbo achar, conforme já verificou Casseb-Galvão (1999). Além de seu sentido básico, pleno, aquele comumente registrado em dicionários de língua portuguesa, por exemplo, "encontrar por acaso ou procurando; descobrir" (FERREIRA, 2001, p. 10), ele é usado como uma estratégia linguística que possibilita o falante veicular seu ponto de vista sobre o que diz, desempenhando, assim, a função modalizadora.

Para atestar isso numa amostra contemporânea, recorremos à chamada fanfiction, narrativa ficcional escrita e divulgada por fãs que se apropriam de enredos e personagens de produtos midiáticos para criarem histórias paralelas ao original. Trata-se de um tipo de

\footnotetext{
1 Trabalho realizado com apoio da Coordenação de Aperfeiçoamento de Pessoal de Nível Superior - Brasil (CAPES) - Código de Financiamento 001.
} 
texto que evidencia pessoas de várias idades compartilharem de um interesse em comum: escrever histórias em que retratam valores da sociedade onde se inserem e através das quais podem criar novas identidades para si e para personagens de universos préexistentes. Nesse processo de criação, o esperado é que a modalização seja uma estratégia recorrente, podendo favorecer o uso do verbo achar em sua função modalizadora.

Com o proposito de contribuir com as pesquisas que tratam dos fenômenos de mudança linguística, o resultado de nossa investigação será apresentado, neste artigo, assim: na primeira seção, expomos alguns pressupostos básicos sobre gramaticalização; na segunda, além de tecer algumas considerações sobre o corpus investigado, descrevemos e analisamos as funções registradas; na terceira, traçamos o continuum empreendido pelo verbo e aplicamos os princípios de Hopper (1991) aos usos constatados. As considerações finais e as referências encerram o artigo.

\section{GRAMATICALIZAÇÃO: DINAMICIDADE E MUDANÇAS NA LÍNGUA}

Em sendo a língua um sistema funcional dinâmico, sujeito a adaptações constantes, a renovação do sistema linguístico é, consequentemente, um processo natural. Contribuem, para isso, fenômenos de mudança, compreendidos, segundo Martelotta (2015, p. 61), como

[...] movimentos que se iniciam no instante em que um indivíduo produz seu discurso para um interlocutor específico, em uma situação comunicativa determinada. Se por um lado a produção discursiva é limitada pelas restrições já consagradas na gramática da língua, por outro constitui um processo criativo no qual o falante recria formas e estende sentidos de acordo com suas limitações cognitivas e as necessidades comunicativas impostas contextualmente.

Um desses movimentos caracteriza o fenômeno conhecido como gramaticalização. Associada aos processos de regularização do uso de uma língua, a gramaticalização, como originalmente é conhecida, se instaura no momento em que uma unidade linguística começa a adquirir propriedades de formas gramaticais ou, se já possui estatuto gramatical, tem sua gramaticalidade ampliada (GONÇALVES et al., 2007). Explicar como esse tipo de mudança se processa nas línguas tem sido o interesse de muitos pesquisadores, e, para isso, conceitos e princípios são propostos. Dentre eles, destacamos alguns que serão relevantes para a nossa análise: a noção de cline/continuum apresentada por Hopper e Traugott (1993) e o conjunto de princípios de Hopper (1991).

A noção de cline ou continuum é proposta para justificar que as mudanças no estatuto dos itens linguísticos não ocorrem de maneira abrupta, mas sim através de transições graduais. Cline ou continuum corresponde ao percurso que um determinado item linguístico segue em direção à mudança. Para Hopper e Traugott (1993), essa escala pode ser usada para explicar os fenômenos linguísticos tanto numa perspectiva histórica quanto sincrônica. $\mathrm{Na}$ perspectiva histórica, o cline se caracteriza como um caminho natural, segundo o qual as formas linguísticas se desenvolvem ao longo do tempo. Na perspectiva sincrônica, o cline serve para explicar os padrões fluidos de uso linguístico, podendo ser considerado como um continum, representado por uma linha imaginária em que, numa 
extremidade, pode, por exemplo, situar uma forma lexical e, na outra, uma gramatical, como ilustra o seguinte percurso (cf. HOPPER; TRAUGOT'T, 1993, p. 103):

- Item lexical de significado pleno $>$ palavra gramatical $>$ clítico $>$ afixo flexional.

Esse percurso indica que a mudança se processa da esquerda para a direita: iniciase a partir do item lexical/pleno (signo linguístico autônomo que expressa uma significação mais concreta) e finaliza com a função mais gramatical, a de afixo (item linguístico de natureza não autônoma, de valor abstrato), colocando em evidência o chamado princípio da unidirecionalidade, definido como "a relação entre dois estágios A e B, tal que A ocorre antes de B, mas não vice-versa” (HOPPER; TRAUGOTT, 1993, p. 100). Ou seja, o que está pressuposto é que uma mudança que se dá numa direção específica não pode ser revertida.

Vale ressaltar, no entanto, que não há um consenso entre os pesquisadores que se dedicam ao estudo da gramaticalização, no que se refere ao princípio da unidirecionalidade. Uns defendem-na como uma hipótese passível de verificação empírica (HOOPER; TRAUGOT'T, 1993), outros, como uma propriedade definitória do processo (HEINE et al., 1991 apud GONÇALVES et al., 2007). Independentemente das discussões convergentes ou não promovidas pelos autores, assumimos, em nosso trabalho, que a unidirecionalidade corresponde a uma estratégia que pode ser usada para explicar os usos e as funções dos itens linguísticos, e que as mudanças por gramaticalização revelam um movimento gradual na passagem de um estágio a outro.

No que se refere a essa passagem, Hopper (1991) propõe cinco princípios que podem ser utilizados como ferramentas para atestar o grau de gramaticalização dos itens. São eles: estratificação, divergência, especialização, persistência e descategorização.

O princípio da estratificação é usado para explicar que, num domínio funcional amplo, novas camadas podem surgir continuamente, e, "quando isso acontece, as camadas mais antigas não são necessariamente descartadas, mas podem permanecer para coexistir e interagir com as camadas mais recentes" (HOPPER, 1991, p. 22). Ou seja, numa escala contínua, sem fronteiras definidas, os itens que estão em processo de mudança não substituem instantaneamente as velhas formas, mas eles se ajustam e passam a conviver e a se relacionar com as funções já existentes.

No que se refere ao princípio da divergência, trata-se da possibilidade de uma mesma forma atender a funções divergentes. Isso quer dizer que, num mesmo recorte temporal, um item lexical que dá origem ao processo de mudança pode manter suas propriedades e permanecer como um elemento autônomo, estando sujeito a sofrer as mesmas mudanças como itens lexicais comuns (HOPPER, 1991).

Quanto à especialização, ela tem relação com o estreitamento da escolha de formas que pertencem a um mesmo domínio funcional. Isso significa que, à medida que a gramaticalização ocorre, a "variedade de escolhas formais diminui e um menor número de formas selecionadas assume significados gramaticais mais gerais" (HOPPER, 1991, p. 22). Quando isso acontece, há um aumento da frequência de uso do item que está mais avançado no processo de gramaticalização. 
A persistência, por sua vez, indica que alguns traços da forma original podem permanecer nos novos sentidos, o que pode ocasionar restrições sintáticas para o uso da forma gramaticalizada. Por mais que uma forma mude, em termos de funções e significados, traços do uso anterior podem ser mantidos.

Por fim, o princípio da descategorização compreende o momento em que "formas sofrendo gramaticalização tendem a perder ou neutralizar os [seus] marcadores morfológicos e os [seus] privilégios sintáticos” (HOPPER, 1991, p. 22), assumindo características de outras categorias. Trata-se, efetivamente, do momento em que o item muda de classe gramatical.

É relevante destacar que o desenvolvimento desses estágios e a efetivação da gramaticalização estão diretamente relacionados à frequência de uso, um dos mecanismos usados para atestar a gramaticalização. Vitral (2006, p. 155) explica que, se um determinado item estiver em processo de gramaticalização, a tendência é: “a) que sua frequência de uso aumente; b) que a sua frequência quando em função gramatical aumente; c) que a sua frequência quando em função lexical diminua”. Sobre a frequência de uso, Tavares (2012, p. 36) também esclarece:

A frequência de uso é um importante fator no estabelecimento e na manutenção da gramática, possibilitando a emergência de novas construções e rotinizando-as. É no momento da interação que o falante organiza os nacos da língua de acordo com a tendência de repetição das experiências passadas, valendo-se de construções lexicais e gramaticais já consolidadas.

A repetição e, consequentemente, a rotinização são estratégias que favorecem a reconfiguração de uma gramática. Captar as frequências com que os falantes usam formas e funções é uma possibilidade de verificar o quão dinâmica é a gramática de uma língua. No dizer de Bybee (2003, apud TAVARES, 2012), gramática não tem existência autônoma, ela existe apenas em uso, logo, o que não é experienciado não faz parte da gramática.

Isso quer dizer que, para atestar a frequência de uso, é necessário recorrer a usos reais de língua, entendendo que é na situação comunicativa, que envolve interlocutores, seus objetivos e o contexto discursivo, que se deve buscar a motivação para explicar os fatos linguísticos. Efetivamente, "é na interação que os usuários manipulam os termos e as expressões disponíveis em sua língua a fim de veicular estratégias comunicativas" (MARTELOTTA, 2011, p. 24), como, por exemplo, expressar sua subjetividade em relação ao conteúdo que quer transmitir, uma propriedade que pode ser evidenciada em usos com o verbo achar.

Assim, a fim de ilustrar como isso se manifesta numa amostra contemporânea, apresentamos, na próxima seção, os resultados de usos efetivos do verbo achar.

\section{SOBRE A FANFICTIONE AS FUNÇÕES}

Fanfiction, ou fanfic, conforme Black (2006, p. 3), é um tipo de 
escrita na qual os fãs usam narrativas midiáticas ou ícones culturais como inspiração para criar seus próprios textos. Em tais textos, os fãs autores imaginativamente estendem o enredo ou a cronologia original, criam novos personagens e/ou desenvolvem novos relacionamentos entre personagens já presentes na fonte original.

Embora seja um gênero de conhecimento restrito, seu surgimento, segundo Cavalcanti (2010), ocorreu em meados do ano de 1920, mas só se popularizou na década de 1960, nos Estados Unidos, por meio do seriado televisivo Star Trek (Jornada nas Estrelas). Mais especificamente, a partir de 1990, por intermédio da web, fãs de todos os tipos e lugares passaram a ocupar os fóruns do ciberespaço, o que permitiu o encontro das chamadas fandoms (comunidades de fãs). Nesses espaços, fãs compartilham e integram modos de admiração, obsessão ou ódio por determinados personagens ou histórias específicas.

Para a pesquisa propriamente dita, escolhemos uma fanfic composta de 11 capítulos da série Stranger Things, intitulada História de volta a Hawquins, dos autores Ramona e Finn (2016), publicada no site https://www.spiritfanfiction.com/, no mês de agosto de 2016. Justificamos a escolha dessa fanfic por se tratar de uma longfic, isto é, uma história de ficção longa (composta de mais de 10 capítulos e 20 mil palavras), partindo da hipótese de que a extensão favoreceria um uso acentuado do verbo achar, principalmente com a função modalizadora, já que se trata de um gênero que permite o autor/escritor da ficção expressar o seu ponto de vista a respeito dos fatos/personagens que envolvem as histórias. Além disso, esse gênero promove a movimentação de pessoas de todo o mundo e de todas as idades, sendo esse lócus ideal para observação de fenômenos de mudança linguística.

Escolhida a fanfic, recortamos as sequências narrativas contendo o verbo achar, sendo cada ocorrência analisada a partir de propriedades específicas, traçadas com base no quadro (1) adaptado de Casseb-Galvão (1999):

Quadro (1): adaptado de Casseb-Galvão (1999)

\begin{tabular}{|c|c|c|c|}
\hline Propriedades & $A C H A R 1$ & $A C H A R 2$ & $A C H A R 3$ \\
\hline Sinônimos & $\begin{array}{c}\text { Encontrar } \\
\text { Descobrir } \\
\text { Deparar com }\end{array}$ & $\begin{array}{l}\text { Apreciar } \\
\text { Avaliar }\end{array}$ & $\begin{array}{l}\text { Supor } \\
\text { Pode ser }\end{array}$ \\
\hline Composição & [SN achar $\mathrm{SN}]$ & [[ SN achar] [que S ]] & [[ SN achar] [que $\mathrm{S}]]$ \\
\hline & Natureza concreta & Natureza abstrata & Natureza abstrata \\
\hline
\end{tabular}




\begin{tabular}{|c|c|c|c|}
\hline Caracterização & $\begin{array}{l}\text { (valor lexical - } \\
\text { pressupõe o } \\
\text { encontro entre } \\
\text { duas entidades do } \\
\text { mundo real) }\end{array}$ & $\begin{array}{c}\text { (valor de } \\
\text { modalizador - } \\
\text { indicando que a } \\
\text { apreciação é } \\
\text { fundamentada no } \\
\text { conhecimento que o } \\
\text { sujeito tem. O falante } \\
\text { tem mais controle } \\
\text { sobre o que diz) }\end{array}$ & $\begin{array}{c}\text { (valor de } \\
\text { modalizador, } \\
\text { evocando incerteza e } \\
\text { dúvida quanto ao } \\
\text { que é dito. O falante } \\
\text { tem menos controle } \\
\text { sobre o que diz) }\end{array}$ \\
\hline
\end{tabular}

Fonte: Galvão (1999)

Pela descrição apresentada no quadro, fica evidente que o verbo achar foi registrado desempenhando três funções no corpus analisado. A primeira delas (achar 1) corresponde ao valor pleno, em que o verbo tem seu significado lexical e seu objeto se refere a algo de natureza concreta, como ilustram (1a) e (1b):

(1) a) Uma hora ou outra, Eleven eu sei que vou achar você. Sei que tudo vai ser diferente dessa vez. Dessa vez, não vou deixar nada ficar entre nós dois. (cap. 11, p. 10).

b) Ele me olhou de olhos arregalados.

- Você ta louco, Mike?

- Quê? Por quê?

- Vai que a gente acha um sutiã. Ele parecia enojado. (cap. 4, p. 5).

Como se pode notar, nesses exemplos, o verbo achar manifesta suas características sintático-semânticas plenas: é o núcleo da predicação com a transitividade determinando a seleção de dois sintagmas nominais $(\mathrm{SN})$ : um que desempenha a função de sujeito (com o traço + animado/agentivo) e outro, a função de objeto direto (com o traço +concreto). Nesses usos, o verbo exprime a noção de encontro de duas entidades do mundo real, podendo ele ser substituído por outros verbos como "encontrar", "descobrir" ou "deparar com". Nos dois casos, existe um agente que tem o controle sobre a ação de procurar: aquele que quer encontrar Eleven (1a) e os indivíduos que podem encontrar o sutiã (1b).

A partir dos exemplos (2) e (3), ilustramos as funções em que o verbo desempenha a função modalizadora. Assumimos, conforme Castilho e Castilho (1993, p. 217), que modalização é uma estratégia linguística usada pelo falante para expressar "seu relacionamento com o conteúdo proposicional", e que esse relacionamento consiste numa "avaliação prévia do falante sobre o conteúdo da proposição que ele vai veicular". Disso, decorre a decisão de o falante expressar seu ponto de vista por meio de apreciação/avaliação ou suposição/dúvida, como se pode notar respectivamente em (2) e (3). 
(2) a) Tem algo nele que não se deixa ser vencido, nem se lhe arremessarem pedaços de concreto em praça pública. Ele sempre faz o que tiver que fazer. Já eu acho que nunca vou ser assim, ao contrário. (cap. 6, p. 6).

b) Eu gostava de fantasiar soluções para aquele dia, coisas que eu poderia ter dito, coisas que eu poderia ter feito. Acho que não fiz o suficiente. Não fui capaz de defendê-la, de protegê-la, quando prometi fazer isso. (cap. 1, p. 4).

Notamos que, diferentemente da função plena (1), em que o verbo seleciona como objeto um SN de natureza concreta, em (2) ele seleciona uma oração encabeçada pelo conectivo que, indicando que o seu sentido é de apreciação, fundamentada a partir do conhecimento que o falante tem a respeito do que está sendo avaliado. No caso de (2a), o falante emite uma opinião acerca de si próprio (... eu acho que nunca vou ser assim), tendo como parâmetro o comportamento de uma outra pessoa (... que sempre faz o que tiver que fazer). O mesmo se pode dizer de (2b), cuja avaliação do falante (Acho que não fiz o suficiente) pressupõe que ele poderia ter feito coisas diferentes em relação a outra pessoa. Ou seja, fatores inerentes ao falante são determinantes da escolha dessa função avaliativa.

(3) a) Mike o que você disse? (percebi que Lucas me olhava curioso)

- O que você disse?

- Sei lá. Acho que alguma bobagem... mas esquece. Do que vocês estão falando? (cap. 6, p. 7).

b) E se eu for de volta a Hawkins, eu espero encontrá-la. Nem que eu precise dar uma volta ao mundo. Nesse mundo ou no mundo invertido, ou sei lá, bater de porta em porta até o fim da minha vida. Talvez eu não me lembre nitidamente, acho que não vou mesmo. (cap. 11, p. 10).

De forma semelhante a (2), em (3) o verbo também seleciona uma oração encabeçada pelo que, com a diferença de que o valor denotado pelo verbo é de suposição, indicando que o falante não tem certeza a respeito dos fatos. Isso fica evidente com a presença de determinados elementos sintáticos nas estruturas. Em (3a), temos a presença da construção sei lá e, em (4b), talvez, reforçando o valor de dúvida expresso pelo achar.

Conforme análise promovida por Casseb-Galvão (1999), podemos dizer que tanto em (2) quanto em (3) o verbo exerce o papel de modalizador epistêmico, aquele que indica o grau de adesão do falante em relação ao que está sendo dito No entanto, as adesões evidenciadas pelos exemplos são diferentes: em (2), a adesão está sendo mediada pelo saber do falante, o que garante um grau de adesão maior ao que está sendo afirmado, o que nos leva a assumir que o falante tem mais controle sobre o que diz; em (3), por sua vez, o nível de adesão por parte do falante é baixo, tendo em vista que o que ele diz está no nível da possibilidade, o que o leva a não se comprometer com o valor de verdade do que está dizendo, portanto, tem menos controle sobre o que é dito. 


\section{SOBRE A FREQUÊNCIA: DO CONTINUUM AOS PRINCÍPIOS DE HOPPER (1991)}

Dos usos evidenciados no corpus, tivemos a confirmação de que o verbo achar desempenha tanto a função plena quanto a modalizadora, porém, com uma frequência bastante deferenciada, como se pode notar nos números da tabela (1):

Tabela 1: Funções do verbo achar

\begin{tabular}{|c|c|c|c|}
\hline \multicolumn{2}{|c|}{ Acho [SN] - Função plena } & \multicolumn{2}{c|}{ Acho [que] - Função modalizadora } \\
\hline OC & $\mathbf{0}$ & OC & \% \\
\hline 05 & 8,2 & 56 & 91,8 \\
\hline \multicolumn{3}{|c|}{ Fonte: as próprias autoras } \\
\hline
\end{tabular}

De fato, a frequência mais expressiva é do verbo achar com a sua função modalizadora $(91,8 \%)$, o que confirma a hipótese de que o gênero fanfiction favoreceria esse uso, que, como vemos na tabela (2), pode indicar dois valores: apreciação e suposição:

Tabela 2: Verbo achar e suas funções modalizadoras

\begin{tabular}{|c|c|c|c|}
\hline \multicolumn{2}{|c|}{ Acho que - apreciação } & \multicolumn{2}{c|}{ Acho que-suposição } \\
\hline OC & \% & OC & \% \\
\hline 20 & 35,7 & 36 & 64,3 \\
\hline
\end{tabular}

Fonte: as próprias autoras

De um total de 56 ocorrências de funções modalizadoras, (64,3\%) são da função que denota dúvida por parte do falante. Adaptando a análise de Casseb-Galvão (1999) aos nossos dados, assumimos que a modalidade evidenciada pelo uso do verbo achar indica uma escala que vai do nível do saber (mais controle) ao nível da probabilidade (menos controle), sendo este último nível o mais recorrente e mais gramaticalizado.

Representando as funções dentro de um continuum de gramaticalização, temos a seguinte direção:

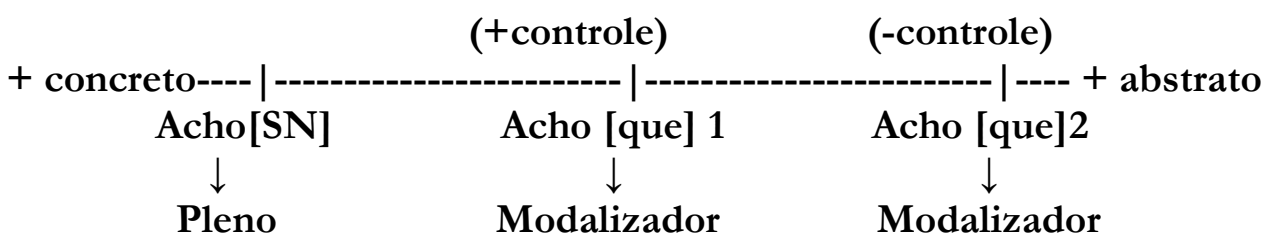


Num ponto mais à esquerda, encontramos o verbo na função plena, com traços + concretos, e, num ponto mais à direita, o verbo na função modalizadora, com traços + abstratos, sendo que, nessa categoria, temos um uso indicando que a modalização segue uma escala que vai do + controle ao - controle.

Esse continum nos permite afirmar, portanto, que os usos do verbo achar no corpus investigado empreendem deslizamentos que são característicos do processo de gramaticalização, podendo ser justificado pela aplicação dos princípios de Hopper (1991).

Primeiro, o princípio da estratificação: novas camadas (acho que 1 e acho que 2) emergiram dentro de um mesmo domínio funcional (contexto de uso), passando a coexistir e a relacionar-se com a camada mais antiga (a de valor pleno). Segundo, o princípio da divergência: indica que a forma original (achar pleno), mesmo sofrendo gramaticalização, e apresentando outras características sintático-semânticas (achar que), permanece no domínio funcional como elemento autônomo. Conforme Hopper (1991), a divergência se aplica aos casos em que um item lexical se torna gramaticalizado em um dado contexto, mas não em outro.

Terceiro, o princípio da especialização: indica que a função modalizadora passa a ter no domínio funcional um caráter especial, ocorrendo uma diminuição das possibilidades de escolha da forma em sua função plena. Isso fica evidenciado pela frequência de uso: o achar modalizador é mais frequente que o achar lexical; por sua vez, o acho que 2 é mais frequente que o acho que 1. Portanto, temos duas especializações sendo evidenciadas num mesmo domínio funcional.

Quarto, o princípio da persistência: tem a ver com a manutenção de traços da forma-fonte na forma gramaticalizada. Dizemos que o verbo achar, em sua composição, seleciona objetos, tanto na função lexical quanto gramaticalizada. No entanto, o que vai diferenciar um do outro é a composição e a natureza desse objeto. $\mathrm{Na}$ função lexical, ele seleciona um SN mais concreto; na função modalizadora, uma oração encabeçada pelo que, com valor mais abstrato. Por fim, o quinto princípio, o da descategorização: caracteriza-se pela perda de traços da forma fonte, que adquire novas características e novas configurações formais e funcionais. No caso da função modalizadora (acho que), ela passou a ter uma nova configuração sintática (seleciona uma oração encabeçada pelo que) e a veicular uma estratégia discursiva, numa função totalmente diferente daquela veiculada em seu sentido pleno, com um movimento que pressupõe o encontro entre duas entidades do mundo real.

Da análise promovida, concluímos: de fato, no corpus analisado, o verbo achar apresenta um comportamento com deslizes funcionais, numa dinâmica que aponta para uma situação de mudança por gramaticalização.

\section{CONSIDERAÇÕES FINAIS}

Levando em conta os usos que os falantes fazem do verbo achar na fanfiction analisada, confirmamos que o verbo achar está sendo usado com funções que ultrapassam o seu valor lexical/pleno (+ concreto), indicando que duas funções modalizadoras estão competindo num mesmo domínio funcional: acho que 1, que denota apreciação feita pelo falante com base no seu saber, e acho que 2, que expressa dúvida por parte do falante. 
Colocados num continuum, esses usos indicam que, de um lado da extremidade, temos a função lexical, achar ( + concreto), e na outra, as funções gramaticalizadas, achar modalizador ( + abstrato). Nessa categoria, por sua vez, notamos também um continuum escalar, que vai do uso que indica + controle, acho que 1, ao uso que denota - controle, acho que 2, sendo esta última situação a mais recorrente e, portanto, a mais gramaticalizada.

Mesmo sendo uma amostra bastante singular, a frequência de uso demonstrada nas tabelas (1) e (2) aponta para uma direção que indica que o verbo achar está se rotinizando na língua com a função de modalização, uma mudança resultante da relação estabelecida entre falantes/ouvintes e situações comunicativas.

Em termos práticos, os resultados de nossa investigação sinalizam que o verbo achar não figura em classe discreta, com limite preciso, pois, como vimos, ele não desempenha apenas a sua função lexical, mas também uma função de natureza discursiva. Assim, no que diz respeito ao ensino desse verbo, ou melhor, a qualquer outro tipo de verbo e a qualquer outra classe gramatical, defendemos a necessidade de se considerar a fluidez e a instabilidade como propriedades essenciais na organização funcional dos sistemas linguísticos. Logo, devemos assumir que, por natureza, as estruturas linguísticas são flexíveis e permeáveis às pressões do uso, estando sujeitas a reelaborações constantes (CASTILHO, 2012).

Nesse sentido, destacamos a importância de se implementar em sala de aula práticas de investigação de uso da língua, com propostas de atividades que envolvam a observação, análise e reflexão, no intuito de o aluno reconhecer que as classes não são fechadas, homogêneas, que podem apresentar deslizamentos funcionais, decorrentes dos usos que os falantes fazem em suas práticas comunicativas.

Captar movimentações e expansões funcionais dos itens linguísticos é uma forma de o aluno compreender que a língua é uma atividade social, que não existe por si mesma, que o sistema linguístico é heterogêneo, maleável e que as movimentações linguísticas são regulares, que os itens da língua estão a serviço do falante, e, por isso, sujeitos a pressões do uso, o que, consequentemente, pode propiciar inovações/transformações, como, por exemplo, a mudança por gramaticalização.

\section{REFERÊNCIAS}

BLACK, R. Language, culture and identity in online fanfiction. In: E-Learning, v. 3, n. 2, 2006.

CASSEB-GALVÃO, V. C. O achar no português do Brasil: um caso de gramaticalização. 170 f. Campinas: Unicamp, 1999. Dissertação [Mestrado em Linguística] Instituto de Estudos da Linguagem. Universidade de Campinas, 1999.

CASTILHO, A. T.; CASTILHO, C. M. M. de. Advérbios Modalizadores. In: ILARI, R. (Org.). Gramática do Português Falado: Vol. II: Níveis de Análise Lingüística. Campinas, SP: Editora da UNICAMP, 1993, p. 213-260. 
CASTILHO, A. T. de. Funcionalismo e gramáticas do português brasileiro. In: SOUZA, E. R. de (Org.) et. al. Funcionalismo linguístico: novas tendências teóricas. São Paulo: Contexto, 2012, p. 17-42.

CAVALCANTI, L. Leitura nos gêneros digitais: abordando as fanfics. Revista Hipertextus. Pernambuco, v. 6, p. 1-15, 2010. Disponível em: <http://www.nehte.com.br/simposio/anais/simposio2010.html>. Acesso em: 10 jan. 2019.

FERREIRA, A. B. de H. Dicionário Aurélio do Século XXI. 4 ed. rev. ampliada. Rio de Janeiro: Nova Fronteira. 2001.

GONÇALVES, S. C. L. et al. Introdução à Gramaticalização: Princípios teóricos \& aplicação. São Paulo: Parábola Editorial, 2007. 206 p.

HOPPER, P. On Some Principles of Gramaticalization. In: TRAUGOTT, E. C.; HEINE, B. (orgs.). Approaches to Gramaticalization. Amsterdam: John Benjamins, 1991, p. 17-36.

HOPPER, P. J; TRAUGOT'T, E. C. Grammaticalization. 2. ed. Cambridge: Cambridge University Press, 1993.

MARTELOTTA, M. E. Mudança linguística: uma abordagem baseada no uso. São Paulo: Cortez, 2011.

MARTELOTTA, M. E. A mudança linguística. In: CUNHA, M. A. F. da; OLIVEIRA, M. R. de; MARTELOTTA, M. E. (Orgs.) Linguística Funcional: teoria e prática. São Paulo: Parábola Editorial, 2015, p. 49-61.

NEVES, M. H. M. Gramática funcional: interação, discurso e texto. São Paulo: Contexto, 2018.

RAMONA; FINN. História De volta a Hawkins. 2016. Disponível em: $<$ https://www.spiritfanfiction.com/historia/de-volta-a-hawkins-6246176>. Acesso em: 05 jan. 2019.

TAVARES, M. A. Gramática emergente e o recorte de uma construção gramatical. In: SOUZA, E. R. de (Org.) et al. Funcionalismo linguístico: análise e descrição. São Paulo: Contexto, 2012, p. 33-51.

VITRAL, L. O papel da frequência na identificação de processos de gramaticalização. Scripta. Belo Horizonte: PUC/Minas. V. 9, n. 18, p. 149-177, 2006. Disponível em: $<$ http://periodicos.pucminas.br/index.php/scripta/article/view/12599 > Acesso em: 20 jan. 2019.

Recebido em: 28/09/2019

Aprovado em: 07/11/2019

Publicado em: 30/04/2020 